\title{
Mato Grosso e Concepción, uma experiência de fronteira no periodo colonial
(século XVIII)
}

Ney Iared Reynaldo*

O presente artigo focaliza o processo de ocupação das terras situadas ao longo do rio $\mathrm{Pa}-$ raguai, desde os primeiros decênios do século XVIII até o final do período colonial. Partindo da constatação de que o controle desse território fazia parte dos projetos expansionistas português e espanhol, analisam-se, inicialmente, as estratégias adotadas pelas duas coroas para ocupar e salvaguardar suas áreas de domínio, até então povoadas por diferentes populações indígenas.

Palavras-Chave: Mato Grosso, Concepción, Fronteira.

This article focuses on the process of occupation of land situated along the River Paraguay, since the first decades of the 18th century un-

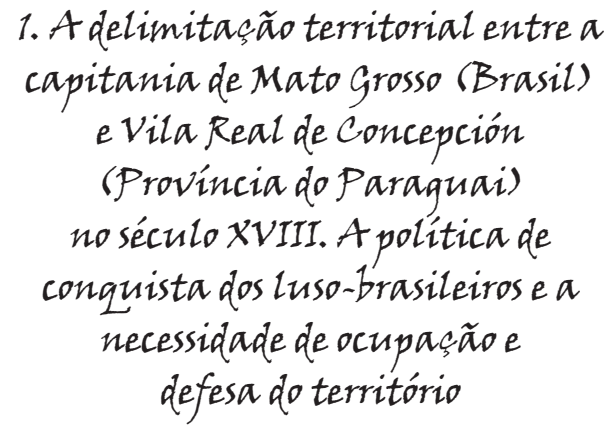

$\mathrm{N}$ essa primeira parte, destaca-se o avanço luso-brasileiro ${ }^{1}$ e as estratégias utilizadas pela Coroa portuguesa para consagrar e defender seu

\footnotetext{
* Mestre em História e Sociedade pela UNESP e doutor em História da América Latina pela UNISINOS, docente do Departamento de História do Campus Universitário de Rondonó-polis, Universidade Federal de Mato Grosso. E-mail: neyhis@yahoo.com.br

${ }^{1}$ A expressão "luso-brasileiro" aqui utilizada se aplica ao português americano; trata-se de uma identificação corrente no século XVIII que fora atribuída aos primeiros bandeirantes paulistas que percorreram no início dos setecentos, os caminhos para o interior de Mato Grosso. Tem-se, como respaldo, a obra de SERRÃO, Joel; MARQUES, A. H. de Oliveira. Nova história da expansão portuguesa: o império luso-brasileiro (1750-1822). Lisboa: Estampa, 1986. Acrescente-se, ainda, a inexistência anterior, na historiografia, de um termo próprio para denominar os súditos portugueses nascidos na América portuguesa e/ou que tinham seus interesses preferencialmente vinculados nessa parte do Império.
} 
til the end of the colonial period. Noting that control of this territory was part of expansionist Portuguese and Spanish projects, analyze initially the strategies adopted by the two crowns to occupy and safeguard your domain areas, until then populated by different indigenous populations.

Key words: Mato Grosso, Concepción, border.

estabelecimento no território. Estratégias essas que envolveram monçoeiros e mineiros inicialmente.

Consideram-se, também, as ações e reações dos espanhóis, especialmente quando fundam Vila Real de Concepción, nas proximidades com Mato Grosso, em uma área rica em erva-mate. A população nativa foi indispensável para a posse efetiva das terras, pois habitava e conhecia profundamente esse território. Nele, são privilegiadas as alianças e/ou os enfrentamentos realizados entre anteriores e colonizadores.

A formação histórica das fronteiras mato-grossense e concepcionera é resultante do expansionismo territorial português e espanhol ocorrido a partir da primeira metade do século XVIII, sendo que a expansão territorial promovida pelos bandeirantes teve participação decisiva nesse processo.

A região do atual Mato Grosso passou a fazer parte dos interesses portugueses no século XVII. Por força do Tratado de Tordesilhas, tratava-se de região pertencente às colônias espanholas. Em 1628, o Pe. Antônio Ruíz de Montoya informou aos seus superiores as declarações de Antônio Raposo Tavares, que afirmara que expulsaria as missões espanholas situadas ao sul do continente americano, porque considerava que essas terras pertenciam ao soberano português e não ao de Espanha².

Esse bandeirante realizou uma grande expedição que percorreu mais de dez mil quilômetros durante três anos. Partindo de São Paulo, dirigiu-se ao sul, à região de Itatim (atual Mato Grosso do Sul), de onde seguiu para o oeste e para o norte, descendo o rio Amazonas até sua foz, no Atlântico. Dos 1.200 homens componentes da bandeira, apenas 58 chegaram a Santo Antônio de Gurupá, nas proximidades de Belém do Pará. O objetivo dessa expedição era não só chegar às minas peruanas, como também estabelecer uma ligação com a bacia amazônica,

${ }^{2}$ CORTESÃO, Jaime. Raposo Tavares e a formação territorial do Brasil. Rio de Janeiro: Ministério da Educação e Cultura, [20--]. 
no que obteve sucesso. Conseguiu, pela primeira vez, ligar as bacias hidrográficas do Prata e do Amazonas.

Oito anos após a restauração do trono português, ocorrida em 1640, os lusitanos já procuravam definir sua política de povoamento e ocupação no interior da Colônia. Em 1716, o bandeirante Antônio Pires de Campos descobriu ouro no ribeirão Coxipó-Mirim, fundando, neste sítio, o Arraial da Forquilha (ou Nossa Senhora da Penha de França). Dois anos depois, chegou ao Arraial outro bandeirante, Pascoal Moreira Cabral, sendo-lhe outorgada, por uma decisão dos habitantes locais, em 1727, a função de Provedor-mor das Minas do Cuiabá. Também nesse mesmo ano, ocorreu a elevação do Arraial da Forquilha à condição de Vila Real do Senhor Bom Jesus de Cuiabá.

Seguindo-se aos descobrimentos auríferos de aluvião ${ }^{3}$ em Cuiabá, novas lavras foram abertas e, com isso, novos garimpeiros, monçoeiros ${ }^{4}$ e aventureiros viram-se, alguns anos mais tarde, atraídos para a região, ampliando o espaço ocupado em direção ao rio Paraguai. Ressalte-se que o ouro de aluvião era proveniente do desgaste das matrizes, que, com as chuvas, era arrastado para os locais baixos. Ele se acumulava no leito dos rios e riachos em depósitos chamados faisqueiras, porque os grãos de ouro faiscavam em contato com o sol.

Em 1748, a fixação de populações junto a esse rio estimulava a prática do contrabando. A prática de contrabando se dava por duas razões: pela possibilidade de intercâmbio do ouro mato-grossense com a prata peruana e para constituir zona de troca de mercadorias no limite entre os dois impérios ${ }^{5}$.

Ao mesmo tempo, já se iniciava o despovoamento de algumas áreas, devido ao declínio da atividade mineradora ${ }^{6}$, a Coroa portuguesa decidiu em 9 de maio de

\footnotetext{
${ }^{3}$ Ver, KEATING, Vallandro; MARANHÃO, Ricardo. Caminhos da conquista: a formação do espaço brasileiro. São Paulo: Terceiro Nome, 2008. p. 178.

${ }^{4} \mathrm{O}$ termo monçoeiros vem de monções, ou seja, expedições exclusivamente fluviais; suas frotas reuniam por vezes 300 a 600 canoas, que transportavam desde sal até artigos de luxo; seguiam roteiros fixos, passando por pontos conhecidos, onde se formavam arraiais e tinham como objetivo chegar às minas de ouro de Cuiabá, além de atender às necessidades da população que vivia da extração aurífera.

${ }^{5}$ Ver mais em MOUTOUKIAS, Zacarias. Contrabando y control colonial. Buenos Aires: CEDAL, 1988.

"O termo "declínio" substitui "decadência", comumente utilizado na historiografia. Therezinha de Jesus Arruda chama atenção para a necessidade de se relativizar esse último: "[....] o ouro não desapareceu totalmente, continuou sendo o motivo da permanência dos primeiros núcleos de po-
} 
1748, pela criação da capitania Geral de Cuiabá e Mato Grosso, a fim de assegurar o domínio desse território. Essa capitania tinha uma característica particular: agregava dois núcleos populacionais. Cuiabá ficou como sede de uma capitania de nome Geral vinculada ao extrativismo aurífero e Vila Bela da Santíssima Trindade, fundada em 1752, como capital de Mato Grosso ${ }^{7}$.

Este período coincidiu com o declínio da exploração mineira no lado espanhol, na região do vale do rio Paraguai. Os anos de 1735 a 1754 foram marcados por uma queda acentuada das atividades nas reservas espanholas, em parte devido ao esgotamento da mão-de-obra indígena, o que foi acompanhado por várias sublevações. Em parte, também, deveu-se às rotas de contrabando que operavam livremente nos limites entre os dois impérios, provocando muitos prejuízos ${ }^{8}$. Estes prejuízos estão associados, sobretudo, a ausência fiscal do Estado, no controle e distribuição de produtos diversos neste ponto de fronteira.

A descoberta de novas jazidas no vale do rio Guaporé em 1730, bem como a atividade do contrabando junto ao rio Paraguai, trouxeram a necessidade de reformar o sistema colonial português. Nesse sentido, o marquês de Pombal, a partir de 1750, iniciou a política de reformulação das práticas comerciais e de ocupação territorial na Colônia.

Os Bourbons, pelo lado espanhol, interessaram-se em resguardar as áreas periféricas de seu Império. Para isso, dispuseram de novos ordenamentos territoriais e promoveram uma série de mudanças fundamentais na visão política espanhola acerca do governo da Colônia ${ }^{9}$. Desse modo, os castelhanos se posicionaram na fronteira, ampliando o número de postos militares, principalmente para impedir o avanço português em direção a vila de Potosí (atual Bolívia), o principal centro produtor de prata da América espanhola.

voamento, bem como do aparecimento de novos." ARRUDA, Therezinha de Jesus. Mato Grosso colonial: pistas para uma abordagem alternativa. Revista Universidade, Cuiabá, ano 3, n. 1, p. 44-45, jan./abr. 1983.

${ }^{7}$ Ver mais FARAGE, Nádia. As muralhas dos sertões: os povos indígenas no rio Branco e a colonização. Rio de Janeiro: Paz e Terra, 1991. p. 123.

${ }^{8}$ Mais detalhes sobre o assunto ver MADARIAGA, Salvador de. El ocaso del imperio español en América. Buenos Aires: Sudamericana, 1955. Ver também, RAVIGNANI, E. El volumen del comercio del Río de la Plata a comienzos de Virreinato (1730-1781). Boletín del Instituto de Investigaciones Históricas, Buenos Aires, n. 28, p. 389-97, 1932.

${ }^{9}$ Cf. GUIMÉRA, Agustín. El reformismo borbónico. Madrid: Alianza Universidad, 1996. 
Esse metal era utilizado no comércio fronteiriço para intercambiar produtos vinculados à economia colonial dos dois impérios: do lado espanhol, exportavam-se couros, charques, sebos e outros subprodutos, que eram comercializados no interior das capitanias da América portuguesa, mas nem sempre consumidos pelos luso-brasileiros. Boa parte destes produtos era reexportado para países do continente europeu. Por sua vez, os comerciantes luso-brasileiros, chamados de "peruleiros" $"$, contribuíam com o comércio clandestino, vendendo seus escravos e gêneros, que eram, posteriormente, comercializados em Buenos Aires, Potosí e ainda outras cidades da região do Prata.

Em 1752, os luso-brasileiros fundaram, na margem direita do rio Guaporé, a Vila Bela da Santíssima Trindade. Essa atitude gerou a primeira reação concreta, por parte dos espanhóis, na defesa de seus interesses. Em 04 de março de 1773, Augustín Fernando de Piñedo fundou ao norte da província do Paraguai, acima do rio Ipané a 330 quilômetros de Assunção, a Vila Real de Concepción, pois entendia que o ato português contrariava o que tinha sido acordado anteriormente pelo Tratado de Madri (1750) ${ }^{11}$.

A fundação desta Vila representou, em parte, para os espanhóis, a recuperação de um território que um século antes se viram obrigados a abandonar, devido às invasões combinadas de índios e bandeirantes. Com isso, pretendiam assegurarem-se contra novas ameaças de expansão luso-brasileiras.

Em 1754, o governo espanhol de Charcas deslocou 5.000 soldados para a fronteira, obrigando o capitão-general da capitania Geral de Cuiabá e Mato Grosso, Antônio Rolim de Moura Tavares, a solicitar reforço ao governador do Pará, a fim de garantir a posse e o domínio do território mato-grossense. O sucessor de Rolim

\footnotetext{
${ }^{10}$ CORTESÃO, Jaime. Op. cit., p. 289, explica que "O tipo social do peruleiro, português que fazia o contrabando com o Peru, enriquecido pelo comércio da prata, teve tamanho prestígio e voga no Brasil e em Portugal, que ainda hoje se conserva a palavra na linguagem portuguesa como símbolo de opulência e exterior aprimorado". Ver, também, CANABRAVA, Alice Piffer. O comércio português no rio da Prata (1580-1640). São Paulo: Editora da Universidade de São Paulo, 1984.

${ }^{11}$ Por este tratado, o limite entre os domínios espanhóis e portugueses, no Mato Grosso, foi traçado a oeste pelo rio Paraguai e, ao sul, pelos rios Ipané-Guaçu, afluente do Paraguai, situado em território hoje da República do Paraguai, e, Iguatemi, afluente do Paraná que tem a foz pouco acima das Sete Quedas. Esse acordo, todavia, foi logo anulado (12 de fevereiro de 1761) e seu substituto (Santo Ildefonso, 1777) tampouco obteve êxito em demarcar as fronteiras.
} 
de Moura, João Pedro da Câmara (1765-1769), ajudado pela guarnição vinda do Pará, enfrentou o presidente da Real Audiência de Chuquisaca à frente de 40.200 homens, deslocados do Peru e de Santa Cruz de La Sierra. Em 1769, o terceiro capitão-general, Luiz Pinto de Souza Coutinho (1769-1771), também lutou contra o general espanhol D. Juan de Pestaña, que tentava ocupar a margem oriental do rio Guaporé.

Em 1783, ocorreu a primeira reclamação oficial espanhola contra a ocupação portuguesa na margem direita do rio Paraguai, abaixo do Jauru. Inácio Flores, na condição de presidente da Real Audiência de Charcas, solicitou a retirada dos portugueses, o que foi ignorado pelo capitão-general da capitania Geral de Cuiabá e Mato Grosso. Então, Juan Francisco de Aguirre, comissário da Comissão de Demarcações de Limites Espanhola ${ }^{12}$, aconselhou o governador Joaquín Alós Brun (1787-1796) que organizasse uma expedição militar para reconquistar os pontos do rio Paraguai que Portugal usurpara.

Essa negociação pode ser melhor consultada na obra Estado y frontera en el Paraguay da argentina Nidia Areces, que versa a respeito das disputas militares no vale do rio Paraguai, entre capitães-generais da capitania de Mato Grosso com a província do Paraguai.

Nesse litígio, Vila Real de Concepción, importante produtora de ervamate (Illex paraguariensis) ${ }^{13}$, se tornara o reduto principal de defesa dos espanhóis junto ao rio Paraguai. Ali, entre os anos de 1788 e 1792, comercializou-se 292.653 pesos deste produto, que era consumido pelas populações, tanto do lado luso-brasileiro, como do lado espanhol ${ }^{14}$.

Dada essa relevância comercial da região, Ricardo Franco de Almeida Serra, sargento-mor de Engenheiros de Portugal, registrou, em 1792, que, nela, havia um forte de pau-a-pique onde viviam, em condições precárias, além de uma

\footnotetext{
${ }^{12}$ AGUIRRE, Juan Francisco de. Diario del Capitán Juan Francisco Aguirre en la demarcación de límites de España y Portugal en la América Meridional. Boletín del Instituto Geográfico Argentino, Buenos Aires, Tomos 7-8, 1911-1912.

${ }^{13}$ Ver, REYNALDO, Ney Iared. O comércio e navegação no rio Paraguai (1870-1940). Cuiabá: Editora da Universidade Federal de Mato Grosso, 2000. p. 215.

${ }^{14}$ VENTRES, Daniel Fretes. Evolución y perspectiva de la estructura social y económica del Paraguay. Estudios Paraguayos, Asunción, v. 2, n. 1, p. 21-45, 1974.
} 
tropa regular, cerca de 1.551 pessoas ${ }^{15}$. Alertou, também, que a ausência de recursos provenientes da Junta da Fazenda Real desestimulava significativamente a entrada de novos colonos oriundos de Assunção. Rivarola (1974) atualiza esses dados conforme a tabela 1, até o ano de 1799, quando registra uma população de 2.227 habitantes.

Tabela 1 - População de Vila Real de Concepción (Província do Paraguai, 1774-1799)

\begin{tabular}{|c|c|}
\hline ANO & POPULAÇ̃̃O \\
\hline 1774 & 170 \\
\hline 1782 & 908 \\
\hline 1785 & 670 \\
\hline 1792 & 1.551 \\
\hline 1799 & 2.227 \\
\hline Total & 5.526 \\
\hline
\end{tabular}

Fonte: RIVAROLA, Domingo et al. La populación del Paraguay. Asunción: Cepes, 1974 p. 121

Enquanto isso, os portugueses seguiam avançando território adentro, criando novas fortificações em locais considerados estratégicos, tanto para a Coroa portuguesa quanto para a espanhola. O governo colonial português expandiu a ocupação da margem direita do rio Paraguai, mediante o estabelecimento do presídio de Miranda (1776) e da povoação de Albuquerque (1778).

Em 1797, a essas posições se juntaria o reconstruído forte de Coimbra, às margens do Paraguai. A fundação deste forte fora realizada em 1773, levando-se em conta as decisões do Tratado de Madri (1750), voltando os rios Paraguai e Guaporé a serem reconhecidos como raias lindeiras entre as duas Coroas.

Segundo Martín:

Las labores demarcadoras ya finalizadas quedaron sin efecto, porque el Tratado de Anulación [1761] mandaba restablecer la situación fronteriza existente en 1750; así, ambas partes demolerían mojones fronterizos, casas y fortificaciones para restablecer las cosas como estaban antes. No obstante, los acontecimientos de los años siguientes dieron un giro distinto, sin llegar a evacuarse

\footnotetext{
${ }^{15}$ WHIGHAM, Thomas L. La yerba mate del Paraguay: 1780-1870. Centro Paraguayo de Estudios Sociológicos, Asunción, p. 131, 1991.
} 
los fuertes y almacenes creados por los portugueses en aquellos años, lo que agudizó el conflicto fronterizo en el Río de la Plata [grifo nosso] ${ }^{16}$.

Num espaço tão disputado, o governo luso-brasileiro passou a utilizar-se de mecanismos para atrair e fixar novos colonos. Povoar, para ele, significava ocupar pontos estratégicos, como a região fronteiriça com os domínios espanhóis: proporcionar, aos moradores, uma atividade econômica que os fixasse realmente, e os integrasse a outras partes da Colônia, transferindo para eles a responsabilidade física pela defesa da fronteira.

Luiz Albuquerque de Melo Pereira e Cáceres (1771-1788), capitão-general da capitania Geral de Cuiabá e Mato Grosso, foi um dos primeiros que estimulou o povoamento do vale do rio Paraguai, tendo fundado ali várias vilas e povoados. Conforme a tabela 2, o resultado dessas ações possibilitou que, em 1771, a população da capitania mato-grossense já fosse superior a 15.765 habitantes e, em 1800, equivalente a 26.690. Vale ressalvar que essa quantificação mensurava tão somente a população branca, registrada em cartório, excluindo-se da contagem todos os indígenas e negros.

Tabela 2 - População da capitania de Mato Grosso 1771 a 1800

\begin{tabular}{|c|c|}
\hline \multicolumn{2}{|c|}{ CAPITANIA DE MATO GROSSO } \\
\hline ANO & POPULAÇ̃̃̃ \\
\hline 1771 & 15.765 \\
\hline 1783 & 20.272 \\
\hline 1786 & 22.310 \\
\hline 1791 & 22.977 \\
\hline 1795 & 24.016 \\
\hline 1800 & 26.690 \\
\hline Total & $\mathbf{1 3 2 . 0 3 0}$ \\
\hline
\end{tabular}

Fonte: Quadro elaborado com dados levantados em LEVERGER, Augusto (Barão de Melgaço). Apontamentos cronológicos da província de Mato Grosso. Instituto Histórico e Geográfico Brasileiro, Rio de Janeiro, Tomo 205, v. 11, n. 9, p. 132-138, out./dez. de 1949. Mapa da população de Mato Grosso de 1771 a 1800.

Considerando o crescimento da população da capitania de Mato Grosso na primeira metade da década de 1790, o comerciante e cronista português Joaquim

${ }^{16}$ MARTÍN, Carmen Martínez. El Tratado de Madrid (1750): aportaciones documentales sobre el Río de la Plata: documentos del Legajo 4798 de la sección de Estado del Archivo Histórico Nacional. Revista Complutense de Historia de América, Madrid, n. 27, p. 283-325, 2001. 
José Ferreira e o sargento-mor Ricardo Franco de Almeida Serra passaram a alertar as autoridades sobre a importância da navegação no rio Paraguai. Este último considerava o rio como uma porta aberta para o interior do Brasil, por serem muitos os seus afluentes, especialmente o Camapuã, que, era a "chave da defesa das capitanias de Mato Grosso, Goiás e São Paulo" ${ }^{17}$. Ainda, ao tomar conhecimento de que os espanhóis haviam iniciado, em 1792, a construção do forte Bourbon $^{18}$, na margem ocidental do rio Paraguai, Almeida Serra alertou para a necessidade de um sistema defensivo, entre Albuquerque e a Baía Negra, que arrematasse de vez a consolidação da soberania lusa sobre essas águas ${ }^{19}$.

Nos últimos anos dos setecentos, os contatos amistosos ou litigiosos entre luso-brasileiros e espanhóis na região de fronteira tenderam a uma redução, motivada, sobretudo, pelo movimento de independência paraguaia. Porém, para além das mencionadas disputas territoriais entre luso-brasileiros e espanhóis, ocorreram também conflitos com os diferentes grupos indígenas que viviam na fronteira.

\section{Os grupos indigenas da fronteira do Mato Grosso e Concepción}

Os diferentes grupos indígenas que se estabeleceram ao longo do vale do rio Paraguai foram alvos dos interesses dos colonizadores espanhóis e luso-brasileiros, quando estes buscaram consolidar seus projetos de fixação e povoamento na região. Os grupos nômades e seminômades possuíam um amplo conhecimento dos rios e das áreas produtoras de folhas de erva-mate, localizadas na região

\footnotetext{
${ }^{17}$ SERRA, Ricardo Franco de Almeida. Extrato da descrição da província de Mato Grosso. Revista Trimestral de História e Geografia, Rio de Janeiro, n. 21, p. 174-175, abr. 1844.

${ }_{18}$ Segundo Ferraz "O governador Alós, da província do Paraguai, em 1792, fundou o forte de Bourbon, depois Olímpo, com vista a impedir aos luso-brasileiros a navegação até a capitania de Mato Grosso" (FERRAZ, Antônio Leôncio Pereira. Memórias sobre as fortificações de Mato Grosso. Revista do Instituto Histórico e Geográfico Brasileiro, Rio de Janeiro, v. 156, n. 8, p. 521, 1929). Ver também VIOLA, Alfredo. El Fuerte Olímpo: su origen y importancia geopolítica. Homenaje al Cincuentenario de la Defesa do Chaco. Anuario del Instituto de Investigaciones Dr. José Gaspar Rodríguez de Francia, Asunción, ano 4, p. 35-45, set. 1982.
}

${ }^{19}$ SERRA. Op. cit., p. 20. 
pantaneira, o que lhes permitia inúmeras incursões e deslocamentos em vários pontos da região ${ }^{20}$.

Esses grupos compartilhavam o espaço onde ocorriam os embates territoriais entre portugueses e espanhóis. Obrigados a se decidirem de que lado ficar, não lhes restava alternativa senão aderir ou resistir à dominação luso-brasileira ou à espanhola ${ }^{21}$.

O contato entre indígenas e portugueses ou espanhóis ocorreu de variadas formas: com algumas tribos, a luta foi contínua e, com outras, foram feitas alianças que permitiam que os colonizadores aumentassem suas tropas nas lutas contra os inimigos, sejam não-índios ou outros indígenas. Os índios aliados formaram, também, parte da mão-de-obra empregada, especialmente nas fazendas de gado e na extração da folha de erva-mate, pois conheciam muito bem a região.

A importância da presença dos indígenas para portugueses e espanhóis era tamanha na região que, muitas décadas depois, em 1848, o comandante do forte de Coimbra Ricardo Franco de Almeida Serra aconselhava que, ao se estabelecerem alianças ou outros tipos de contatos, se mantivesse um prudente equilíbrio nas relações com os indígenas. Sustentava que estes seriam "incapazes de abraçar solidamente o cristianismo, de manter-se de forma permanente em aldeias, de entregar-se à exaustão do trabalho forçado na agricultura, de conviver pacificamente nas sinceras alianças na comunidade portuguesa, se não abandonassem seus pérfidos princípios"22. Entendia-se por estes "pérfidos princípios" tudo aquilo que ia na contramão dos ensinamentos cristãos ocidentais, chegando Almeida Serra a propor, "inclusive, a destruição das culturas, dos povos indígenas, forçando-os a submeter-se a novos valores culturais e civilizados" 23 .

\footnotetext{
${ }^{20}$ Os grupos indígenas localizados fora da região do Pantanal e do rio Cuiabá abaixo não serão aqui tratados, mesmo que tivessem mantido algum tipo de contato com os colonizadores, pois isso fugiria ao propósito desse trabalho.

${ }^{21}$ ALMEIDA, Maria Regina Celestino de. Metamorfoses indígenas: identidade e cultura nas aldeias coloniais do Rio de Janeiro. Rio de Janeiro: Arquivo Nacional, 2003. p. 27.

${ }^{22}$ SERRA, Ricardo de Almeida. Parecer sobre o aldeamento dos índios Payaguá e Guaycuru, com a descripção dos seus usos, religião e costumes. Revista de História e Geografia do Instituto Histórico e Geográfico Brasileiro, Rio de Janeiro, Tomo 7, n. 33, p. 211-232, ago. 1843.

${ }^{23}$ JARDIM, Ricardo Gomes. Continuação do parecer sobre os índios Guaicuru e Guaná, etc. Revista Trimestral do Instituto Histórico e Geográfico Brasileiro, Rio de Janeiro, Tomo 6, n. 19, p. 369-370, 381 e 386, 1850.
} 
Ao se observar a história dos contatos entre portugueses, espanhóis e índios nas regiões mato-grossenses e concepcionera, verifica-se que a população indígena diminuiu sensivelmente, sendo que poucos permaneciam no local já nos fins do século XIX. Na atualidade, constatando-se os minoritários grupos de sobreviventes ao processo de ocupação e extermínio, é quase impossível ter-se uma idéia do que significaram na época colonial.

A posse gradual de terras, a formação de fazendas, a utilização de mão-deobra indígena e as distintas modalidades de exploração do trabalho implementadas permitiram o controle dos colonizadores europeus sobre os usos dos recursos básicos e sobre a produção da região. Essa transição, que trouxe consigo crescentes pressões sobre os índios, visando sua submissão em uma área de fronteira, provocou, ao mesmo tempo, o deslocamento dos nativos da zona portuguesa para a espanhola, ou vice-versa.

Um exemplo desse movimento são os grupos que se localizavam às margens do rio Paraguai e seus afluentes e que mantiveram contatos com os colonizadores ${ }^{24}$. Entre eles, estão a dos Laiana e Terena ${ }^{25}$ que, organizados em aldeias, viviam nas imediações dos rios Miranda e Aquidauana, no sul da capitania de Mato Grosso.

Esses índios foram, forçosamente, integrando-se aos não-índios que avançavam pelos seus domínios. A maior parte deles trabalhava nas fazendas de gado. Do lado paraguaio, em Vila Real de Concepción, os Terena estiveram assentados em Naranjaty, nas proximidades de Horqueta, até 1841. Seus cultivos se estendiam até o rio Aquidaban e competiam com os dos criollos, que os acusavam de roubo de mulheres e de gado, além de outros distúrbios ${ }^{26}$.

\footnotetext{
${ }^{24}$ Neste ponto, convém esclarecer a convenção adotada no presente trabalho, quanto à grafia dos nomes de grupos. Segundo a antropóloga Joana Fernandes, a Associação Brasileira de Antropologia, reunida em 1953, estabeleceu algumas convenções que buscaram uniformizar os nomes dos grupos indígenas, que até então eram escritos de diversas formas. Convencionou-se também que os nomes das tribos indígenas devem ser escritos com letra maiúscula, não devem ser flexionados nem em gênero, nem em número (FERNANDES, Joana. Índio - Esse nosso desconhecido. Cuiabá: Editora da Universidade Federal de Mato Grosso, 1993. p. 47).

${ }^{25}$ Mais sobre os Terena e Laiana ver OBERG, Kalervo. The Terena and the Caduveo to Mato Grosso. Washington: [s.n.], 1949.

${ }^{26}$ ARECES, Nidia R. La frontera entre Mato Grosso y Concepción: de tierra de indios bárbaros a espacio militarizado y colonizado. Rosário: Centro de Estudios sobre Diversidad y Consejo de Investigaciones de la Universidad Nacional de Rosario, 2006 (mineo.).
} 
Dentre os povos que habitavam a região, os Paiaguá merecem destaque, por dois motivos: sua habilidade na navegação dos rios com suas canoas e a guerra contínua que travaram contra os colonizadores ${ }^{27}$.

Os primeiros registros de que se dispõe sobre estes índios remontam ao início da conquista espanhola no rio Paraguai, no século XVI, quando eles controlavam a zona do Paraguai e os pantanais mato-grossenses. Segundo Corrêa Filho, em 1725, os Paiaguá atacaram e destruíram a monção de Diego de Souza, que tentava chegar a Cuiabá com vinte embarcações e 600 pessoas $^{28}$.

Entre os portugueses, havia uma preocupação intensa com as freqüentes investidas dos Paiaguá. Estes indígenas, para defenderem seus territórios, combatiam as monções, as fazendas, os mineiros e os viajantes, sendo que as autoridades coloniais luso-brasileiras e espanholas faziam, de forma periódica, expedições militares ${ }^{29}$ contra eles. Em meados do século XIX, os Paiaguá habitavam o Chaco paraguaio, sendo sua extinção, no Brasil, atribuída à guerra que travaram contra os Guaicuru, em finais do XVIII ${ }^{30}$.

Outro grupo, o dos Caiuá, era um dos que integravam as Missões do Guairá, localizadas ao sul da capitania de Mato Grosso. Após a destruição destas, estes índios se estabeleceram na zona compreendida entre os rios Miranda, Ivinhema, Iguari, Xeres, Paraná e Paraguai. Por serem "pacificados", ressalte-se que os confrontos de colonizadores com os indígenas fizeram com que a "pacificação" fosse um verdadeiro eufemismo para extermínio ${ }^{31}$. Pois sofreram o contínuo ataque de outras tribos como os Paiaguá, Guaicuru, Terena e Laiana, que roubavam suas mulheres e crianças e destruíam suas aldeias.

\footnotetext{
${ }^{27}$ Ver mais em MOURA, Carlos Francisco. A contribuição naval à formação territorial do extremo oeste (Mato Grosso, Rondônia e Mato Grosso do Sul). Rio de Janeiro: [s.n.], 1986. Veja-se, também, DEL PRIORE, Mary; GOMES, Flávio (Org.). Os senhores dos rios. Amazônia, margens e histórias. Rio de Janeiro: Campus, 2003.

${ }^{28}$ CORRÊA FILHO, Virgilio. História de Mato Grosso. Várzea Grande: Fundação Júlio Campos, 1994.

${ }^{29}$ Eram expedições militares fluviais que visavam dar proteção aos monçoeiros contra os ataques ribeirinhos dos Paiaguá.

${ }^{30}$ MOUTINHO, Joaquim Ferreira. Notícia sobre a província de Mato Grosso: seguido de roteiro de viagem de sua capital a São Paulo. São Paulo: Tipografia Henrique Schroeder, 1869. p. 194.

${ }^{31}$ Cf. CARVALHO, Silvia Schmuziger. Chaco: encruzilhada de povos e melting pot cultural: suas relações com a bacia do Paraná e sul mato-grossense. In: CUNHA, Manuela Carneiro da (Org.). História dos índios no Brasil. São Paulo: Companhia das Letras, 1997. p. 457.
} 
Os Guaicuru ${ }^{32}$ eram procedentes do Chaco Boreal, situado no sul da Bolívia, a oeste do Paraguai, norte da Argentina e oeste do Brasil, e ocuparam os locais anteriormente habitados pelos Paiaguá. Isto possibilitou uma mistura lingüística, conforme constata Braustein:

Muchos datos parecen indicar que en el Chaco se han producido diversos y complejos fenómenos de contacto, interferencia y mezcla lingüística. Esto es altamente coherente con lo que sabemos sobre la organización social y la etnohistoria de los chaqueños ${ }^{33}$.

Esses indígenas utilizaram o cavalo ${ }^{34}$, o que permitiu que percorressem as terras compreendidas entre os rios Curuguati e Ipané-Guaçu (região rica em erva-mate), até o vale do Emboteteí, pelos campos de Vacaria ${ }^{35}$. Depois dos portugueses serem atacados por eles, o capitão-general da capitania de Mato Grosso, João de Albuquerque de Mello Pereira e Cáceres (1789-1796), conseguiu, em 1791, fazer uma aliança. Este fato permitiu reduzir os ataques que os Guaicuru organizavam contra as fazendas estabelecidas no sul de Mato Grosso.

Os Caiapó constituíam numeroso grupo aldeado na capitania de Mato Grosso. Habitavam preferencialmente os terrenos entre os rios Paraná e Paranaíba e as cabeceiras do São Lourenço e do Taquari; poucos viviam nas margens do rio Piquiri e outros tantos se encontravam nas proximidades do porto do Paranaíba e na estrada que ia para a capitania de São Paulo.

${ }^{32}$ Sobre estes índios o engenheiro português Luiz D`Alincourt faz uma descrição detalhada dos Guaicuru em sua obra Rezultado dos trabalhos e indagações estatísticas da província de MattoGrosso. Annais da Biblioteca Nacional do Rio de Janeiro, Rio de Janeiro, v. 8, p. 39-142, 18801881. Para saber mais, a respeito dos primeiros contatos, ver CABEZA DE VACA, Alvar. Naufrágios e comentários. São Paulo: L\&PM, 1987. p. 158.

${ }^{33}$ BRAUSTEIN, José A. Nuevos rumbos de la etnolingüística chaqueña. Revista do Instituto de Ciencias Antropológicas, Buenos Aires, p. 63-94, 1999.

${ }^{34} \mathrm{O}$ cavalo foi introduzido na região platina pelos espanhóis da expedição de Pedro de Mendonza. A maioria dos grupos indígenas, ao verem estes animais serem montados, assustavam-se, e algumas, apavoradas, fugiam ou rendiam-se. $\mathrm{O}$ fato dos grupos indígenas charquenhos, terem conseguido domesticá-los e usá-los na luta contra os conquistadores, demonstra um processo inverso do que normalmente ocorreu entre índios e brancos. Sobre esse assunto, ver COSTA, Maria de Fátima. História de um país inexistente: o Pantanal entre os séculos XVI e XVIII. São Paulo: Kosmos, 1999. p. 50-51.

${ }^{35}$ A região recebe o nome de Campo da Vacaria, devido à existência de registro da presença de gado no sul de Mato Grosso, no ano de 1697; para mais detalhes, ver PROENÇA, M. Cavalcanti. No termo de Cuiabá. Rio de Janeiro: MEC/INL, 1958. p. 68-69. 
Os colonos temiam os índios Caiapó, que segundo Barros "valendo-se das noites, queimava as casas e matava a gente, e assim ninguém se animava a lançar roças e viver em semelhante altura, salvo se fosse algum homem de poder e vivesse muito bem entrincheirado, e com bastantes armas" ${ }^{36}$. Suas investidas faziam dos forasteiros e das monções seus alvos preferidos, pois eles os matavam e se apropriavam de todos os mantimentos provenientes da capitania de São Paulo. Várias expedições foram organizadas pelas autoridades portuguesas para contêlos e, desta forma, liberar as rotas fluviais que conduziam às minas do Cuiabá.

Havia, ainda, os Caduveo, que se localizavam perto do presídio de Miranda e nas margens do rio Paraguai, abaixo do forte de Coimbra. Eram tipicamente guerreiros e, quando atacavam outros indígenas, sempre capturavam prisioneiros para serem utilizados como escravos nas suas aldeias e culturas, além de os utilizarem como objetos de troca por cavalos e gado.

Do lado espanhol da fronteira, os Mbaiá ${ }^{37}$ ocupavam uma grande extensão desde o Orinoco até o rio da Prata. Seu centro organizado mais importante localizava-se na província do Paraguai. Susnik analisa o "espírito belicoso" dos Mbaiá como uma categoria sócio-mental da violência, pois sua agressividade reveste-se de uma conduta cultural, cuja exaltação do vigor dos guerreiros garantia a sobrevivência do grupo. O que não impedia, também, sua facilidade de se adaptar aos espanhóis e aos portugueses, inclusive aos jesuítas, os quais organizaram missões na região do Itatíns, por eles povoada ${ }^{38}$.

Muitos outros grupos viviam em área fronteiriça, tais como os Guaná, vizinhos dos Paiaguá e Porrudo, que dominavam o alto do rio São Lourenço, na bacia do rio Paraguai. Estes grupos resistiram à presença luso-brasileira, mas, aos poucos, foram integrados ao trabalho e passaram a fazer parte da mão-de-obra

\footnotetext{
${ }^{36}$ BARROS, Manuel de. Roteiro verdadeiro das minas do Cuiabá [...] com os dias da navegação e travessia, que se costumam fazer por mar (sic), e terra apud TAUNAY, Alfredo d'E. Relatos monçoeiros. São Paulo: Melhoramentos, 1988. p. 149-169.

${ }^{37}$ Segundo J. Labrador Sanches, a palavra Mbayá é da língua Guarani e significa esteira. SANCHEZ, J. Labrador. El Paraguay católico. Buenos Aires: Imprenta de Coni y Hermanos, 1959. v. 1, p. 268. Acerca do assunto, consulte-se também HERBETS, Ana Lúcia. História dos MbayáGuaicuru - panorama geral. Revista de História Fronteiras, Campo Grande, v. 2, n. 4, p.39-76, jul./dez. 1998.

${ }^{38}$ SUSNIK, Branislava. Los aborígenes del Paraguay: etnohistoria de los chaqueños. Asunción: Museo Etnográfico Andrés Barbero, 1981. p. 9-10.
} 
das fazendas da região. A princípio, estavam voltados fundamentalmente para atividades de carregamento e tripulação de canoas, serviços militares, lavoura e corte de lenha e, com o surgimento da pecuária no sul da capitania de Mato Grosso, passaram a ser maciçamente empregados nessa atividade ${ }^{39}$.

As formas de territorialidade, ou o uso que os indígenas faziam das ocupações para assegurar sua sobrevivência e garantir sua reprodução material e simbólica, chocaram-se com os interesses dos fazendeiros e escravistas, no caso luso-brasileiro, e com o dos ervateiros e pequenos povoados, com relação aos espanhóis ${ }^{40}$. As situações conflituosas se produziam preferencialmente em espaços de importância para os colonizadores, tais como as proximidades das vilas, os campos de Iguapós, Miranda, Albuquerque e Coimbra, bem como a região entre os fortes de Curuzu, San Carlos, Apa, Bourbon e Baluarte de Itá-Ibaité.

Convém lembrar que essas disputas territoriais já vinham ocorrendo entre os diferentes grupos que viviam na região. Isso, de certa forma, contribuiu para facilitar, aos não-índios, a constituição de diferentes alianças.

No desenvolvimento deste item, explicamos como e porque a expansão colonizadora foi colocando em xeque a organização indígena. Advertimos que as pressões sobre os indígenas exerceram-se de acordo com as modalidades surgidas nas proximidades, como: as expedições punitivas e as ações defensivas. Além disso, os ervais, o gado e a terra envolveram não-índios nas relações de alteridade, não havendo, para os protagonistas, outra opção que não fosse escolher entre um ajuste pacífico ou a guerra. Considere-se, por fim, a existência de uma franja intermediária na fronteira que era ultrapassada continuamente pelos nativos ${ }^{41}$.

É justamente nessa franja intermediária que os nativos são "aceitos" no universo crioulo, seja pelas visitas diplomáticas, de trocas e relações mercantis, prestação temporária de trabalho em fazendas, ou livre instalação nas vilas e

\footnotetext{
${ }^{39}$ Ver BARTOLEMÈ, Miguel Alberto. Los Guaná y sus jefes. Revista Suplemento Antropológico, Asunción, v. 4, n. 2, p. 161-184, 1969.

${ }^{40}$ ARECES, Nidia R. Estado y frontera en el Paraguay: concepción durante el gobierno del Dr. Francia. Asuncíon: Litocolor, 2007. p. 68.

${ }^{41}$ Cf. FERNANDES, Florestan. A Organização social dos Tupinambás. São Paulo: Hucitec, 1989.
} 
povoados. Cada uma destas vias de contato proporcionava aos índios ampliação de seus conhecimentos na sociedade branca. As negociações diplomáticas que se davam procuravam ocultar as estratégias políticas, com as quais cada um procurava tirar maior benefício. A curto prazo, os indígenas obtiveram favores dentro do esquema da reciprocidade e para os brancos a garantia de uma trégua ou paz duradoura, no marco da legalidade do Estado paraguaio. Em particular, essas trocas revelaram o grau de intimidade e laços diretos que uniam os indígenas com os povoadores na fronteira.

Constatamos, assim, um fenômeno cultural que vinculava aos crioulos, os mestiços e índios. Observamos os grupos indígenas divididos entre a colaboração com os não-índios e a resistência, a negociação e o conflito. Não obstante, em nenhum momento, esses povos lograram coordenar decisões ao nível do conjunto étnico, pelo contrário, quando as invasões ocorreram em repetidas ocasiões, muitas eram denunciadas pelas próprias tribos não envolvidas nessas negociações.

Verificamos, todavia, outra maneira de vinculação, neste caso violenta: a guerra não formal. Com a recolonização, aumentaram os choques e as guerras interétnicas de diferentes grupos indígenas que tiveram a saída na aculturação, na redução de povos indígenas ou na migração forçada para outros territórios.

Sendo assim, no final do século XVIII, frente às pressões colonialistas, muitos grupos nativos deslocaram-se e dispersaram-se, integrando-se a outros grupos. Houve, ainda, hostilidade na forma de saques às propriedades ou ataque às caravanas de ervateiros. A existência de variadas alternativas indicava, temporariamente, um mútuo fracasso nas tentativas de aniquilação do adversário, ocasionando a perda gradual da capacidade de resposta indígena, quando os governos centrais e as forças regionais mantinham na fronteira uma política oscilante entre o enfrentamento e a negociação, com o objetivo último de eliminar os indígenas.

\section{O comércio como agente de contatos entre Luso-brasileiros e espanhóis}

O terceiro item privilegia a atividade comercial que se desenvolveu ao longo do rio Paraguai e seus afluentes, a qual proporcionou diferentes formas de 
contato entre luso-brasileiros, índios e espanhóis na fase final da colonização. Com destaque a prematura e sempre crescente vinculação comercial da região sul das capitanias Gerais de Cuiabá e Mato Grosso com outras do Brasil, como São Paulo, Goiás e Minas Gerais.

A atividade comercial foi outro fator que propiciou a ocupação do espaço junto ao rio Paraguai, tanto por portugueses quanto por espanhóis. O comércio de variados artigos em troca do ouro mato-grossense e da prata de Potosí permitiu que ali se estabelecesse uma prática tanto de contrabando, a princípio bastante combatida pelas duas Coroas, como de um comércio legal que, gradativamente, foi se fazendo presente na região.

Já por volta de 1744, tem-se notícia da prática do comércio ilegal no vale do rio Paraguai. Segundo os registros das Minas do Cuiabá, foi nesta localidade que se organizou "uma maloca de gente boa com muitas fazendas, que, a pretexto de

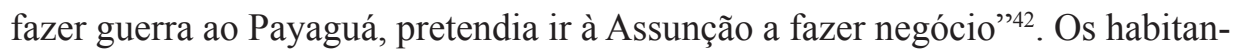
tes dos dois lados da fronteira viam-se, por sua situação desfavorável, compelidos a se buscarem mutuamente, a procurarem canais de comércio, gerando um intercâmbio que se tornaria, mais tarde, do interesse da Coroa portuguesa. Como assinala Volpato, essa ação,

Visava a introduzir nas colônias espanholas os mais variados produtos, tendo as fortalezas como ponto de apoio. Desenvolveu-se na fronteira, assim, uma teia de interesses comerciais: manufaturas e escravos por prata, gado vacum, cavalar, muar e gêneros de abastecimento por ouro, que constituíam o principal do fluxo ${ }^{43}$.

Conforme observou Lenharo, as atividades de comércio ilícito não se estabeleciam numa só direção; ao contrário, se elas visavam carrear a prata dos domínios espanhóis, o ouro mato-grossense era cobiçado pelas povoações espanholas ${ }^{44}$. Se esse comércio fronteiriço proporcionou acumulação da economia mercantil metro-

\footnotetext{
${ }^{42}$ SÁ, Joseph Barbosa de. Relação das povoaçoens do Cuyabá e Matto-Grosso de seos principios thé os prezentes tempos. Cuiabá: Editora da Universidade Federal de Mato Grosso, 1975. p. 43.

${ }^{43}$ VOLPATO, Luíza Rios Ricci. A conquista da terra no universo da pobreza: formação da fronteira oeste do Brasil, 1719-1819. São Paulo: Hucitec, 1987. p. 58, 60-61.

${ }^{44}$ LENHARO, Alcir. Crise e mudança na frente oeste de colonização: o comércio colonial de Mato Grosso no contexto da mineração. Cuiabá: Editora da Universidade Federal de Mato Grosso, 1982. p. 37.
} 
politana, algum excedente também ficou na capitania mato-grossense, retido pelos comerciantes locais e proprietários de lavras. Como decorrência dos lucros obtidos na atividade mineradora, a agricultura e a pecuária puderam surgir na economia mercantil regional.

Tais transações mercantis envolveram diferentes espécies de produtos, como o ouro, a prata, o diamante e o escravo, contribuindo, dessa maneira, para o reordenamento do conjunto das forças produtivas da região mineradora. Propiciou-se, assim, que os comerciantes acumulassem capital suficiente para que, com o lucro obtido nessas transações, independentemente do declínio da mineração, pudessem investir em terras, gado, engenhos e escravaria na capitania. Dessa forma, ampliaram-se os interesses na permanência desses comerciantes em terras do Mato Grosso.

É importante ressaltar que o intercâmbio entre luso-brasileiros e espanhóis não se desenvolveu apenas através do comércio ilícito. A circulação legal de mercadorias diversas, procedentes do litoral brasileiro, foi valorizada em todo o vale do rio Paraguai. O contrabando e o comércio legal motivaram a preocupação dos governantes com a construção de uma infra-estrutura mínima que permitisse a continuidade desse fluxo mercantil, bem como com a edificação de fortificações que, além da função militar, favorecessem a produção de alimentos para o abastecimento da capitania, possibilitando, portanto, a fixação de novos povoamentos na região ${ }^{45}$.

E ainda, a instalação de praças e postos comerciais, desde o final do século XVIII, possibilitou a expansão do território luso em direção ao vale do rio Paraguai e sua ocupação prolongavam-se pelo lado espanhol (Paraguai), de áreas que iam desde Assunção passando por Curuguati ${ }^{46}$, até as porções setentrionais do Mato Grosso. Eles permitiram o comércio entre os dois domínios. Tal comércio, embora em mínima escala, concentrava-se na compra, por parte dos luso-brasi-

\footnotetext{
${ }^{45}$ No dicionário da língua portuguesa, "contrabando" designa introdução clandestina de mercadorias que estão sujeitas a cobrança de direitos a favor do tesouro público; mercadoria introduzida fraudulentamente; ação ilícita praticada clandestinamente ou comércio proibido (FERREIRA, Aurélio Buarque de Holanda. Dicionário básico Aurélio da língua portuguesa. Rio de Janeiro: Nova Fronteira, 1988. p. 374).

${ }^{46}$ Povoação paraguaia estabelecida, em 1715, era forte produtora de erva-mate e do comércio de compra e venda de muares e cavalos.
} 
leiros, de cavalos, bestas e gado bovino fornecidos pelos hispano-americanos, em troca, forneciam-se aos espanhóis artigos manufaturados, ferrarias, etc ${ }^{47}$.

Estas praças e postos, como o de Iguatemi, não eram necessariamente apenas militares, constituíam núcleos importantes para o sistema de relações de trocas comerciais e para o contrabando, envolvendo espanhóis e luso-brasileiros. Serão justamente nesses micro-espaços que se darão estas atividades, muitas das quais tendo o consentimento dos comandantes e praticadas por toda população fronteiriça. Fazendeiros e militares vendiam, clandestinamente, gados e mulas, muitas vezes com a intermediação dos indígenas.

Tendo em vista esse comércio entre lusos e espanhois, Vila Real de Concepción, aos poucos, foi abandonando o seu antigo propósito de posto militar de defesa do território castelhano. Inicialmente, deu lugar a estâncias ${ }^{48}$ e converteu-se, depois, num pequeno povoado dedicado a atividades comerciais lícitas e ilícitas, próprias de fronteira. No final do século XVIII e no início do XIX, com os acirramentos dos antagonismos entre Buenos Aires e Assunção, foi notório o relaxamento com a sua defesa.

Ainda em relação ao redimensionamento dos espaços das fronteiras, proveniente do comércio entre luso-brasileiros e espanhóis, com o advento da mineração, ocorrida em meados dos setecentos, migraram, para o sul da capitania de Mato Grosso, mineradores e monçoeiros oriundos do litoral brasileiro. Estes se utilizavam das monções ${ }^{49}$ para abastecerem as vilas e povoados com diferentes artigos

\footnotetext{
${ }^{47}$ SOUZA, Cândido Xavier de Almeida e. Discripção diária dos progressos da expedição destinada da Capitania de Sam Paulo para as fronteiras do Paraguai, em 9 de outubro de 1800. Revista do Instituto Histórico e Geográfico Brasileiro, Rio de Janeiro, v. 202, p. 3-132, jan./mar. 1949.

${ }^{48}$ Jean Borde e Mário Gongora explica que o termo "Estância" surgiu no século XVII aos grandes domínios e foi substituído no século seguinte para "Hacienda". É uma troca que coincide com a transição da economia rioplatense de pastoril do século XVII a agropecuária do XVIII. Mas se tem empregado indistintamente os dois termos para a criação bovina, durante todo o século XIX (BORDE, Jean; GONGORA, Mário. Evolucion de la propriedad rural en el Valle del Puangé. Santiago do Chile: [s.n.], 1956. p. 58 apud PAOLI, Juan Bautista Rivarola. La economia colonial. Asunción: Litocolor, 1986. p. 382).

${ }^{49} \mathrm{O}$ vocábulo "monção", segundo Antenor Nascentes, é de origem árabe. O termo mausian era usado na linguagem dos marítimos como tempo favorável para a viagem às Índias, devido ao vento que soprava do oeste. Seu uso generalizou-se entre os navegadores lusitanos durante suas incursões ao Oriente. O Novo dicionário da língua portuguesa de Aurélio Buarque de Holanda traz, além dos sentidos etimo-
} 
como: sal, azeite, ferramentas, tecidos, armas etc. O comércio monçoeiro sul partia do interior paulista em Porto Feliz (antiga Araritaguaba) para Cuiabá ${ }^{50}$.

Conforme demonstrado na figura 1 acima, no trajeto monçoeiro sul compreende as áreas banhadas pelos rios Tietê, Paraná, Paraguai, Coxim, Taquari, São Lourenço e Cuiabá.

Os conhecimentos fluviais da época já permitiam a utilização de uma grande multiplicidade de rios. Dos afluentes do Paraná, pelo lado da capitania de São Paulo, podia utilizar-se tanto o Tietê como o Paranapanema; entre os afluentes do Mato Grosso, tinha-se o Sucuriú, o Verde, o Pardo (e seu formador Anhanduíguaçú), o Ivinhema e seus formadores (Vacaria e Brilhante). Entre os afluentes orientais do rio Paraguai, podia-se escolher o Miranda, o Aquidauana, o Taquari ou mesmo o São Lourenço.

Em todos os caminhos, contudo, havia que percorrer por terra trechos mais ou menos extensos: eram os chamados varadouros. Tratava-se de pequenos refúgios que permitiam percorrer um trecho da rota por terra, para se alcançar outro afluente ou subafluente de um rio; essas passagens serviam também para despistar os ataques indígenas ou na busca de percursos menores para se alcançar a Vila de Cuiabá.

Isso se deve ao fato de que, em Mato Grosso, coexistem dois tipos de formações: a de planalto, que compreende parte da bacia sedimentar do rio Paraná e a de planície, no vale do rio Paraguai: elas são separadas pela serra do Maracaju, que corta a região quase ao meio, no sentido norte-sul, e muda de nome, ao sul, nas cabeceiras do rio Apa, para serra do Amanbahy, já em território paraguaio.

lógicos e gerais do termo, a sua conotação histórica, própria do Brasil, referindo-se às "expedições que desciam e subiam rios das capitanias de São Paulo e Mato Grosso, nos séculos XVIII e XIX, pondo-as em comunicação". (HOLANDA, Aurélio Buarque de. Dicionário etimológico da língua portuguesa. Rio de Janeiro: Livraria Acadêmica, 1955. p. 1.525).

${ }^{50}$ AYALA, S. Cardoso; SIMON, F. (Org.). Álbum Graphico do Estado de Matto-Grosso. Corumbá: Hamburgo, 1914. p. 258. Conforme, SUDÁRIO, Julio da Silveira. Araritaguaba e o seu primeiro Capitão-Mor. Revista Arquivo Municipal de São Paulo, São Paulo, ano 6, v. 70, afirma que: “o nome de Porto Feliz veio com a Vila em 20 de dezembro de 1797 [...]. Grande foi o prestígio de Porto Feliz no tempo das monções. Da florescente vila partiu a maioria das expedições. [...] seu declínio ocorreu quando as descidas passaram a ser feitas de Piracicaba. Golpe de morte receberam as monções históricas quando se abriram as comunicações pelos rios Paraguai e Paraná, feitas a vapor. Praticamente a comunicação fluvial em Porto Feliz não existia em 1838” (p .60). 
Figura 1 - Trecho percorrido pelas monções sul

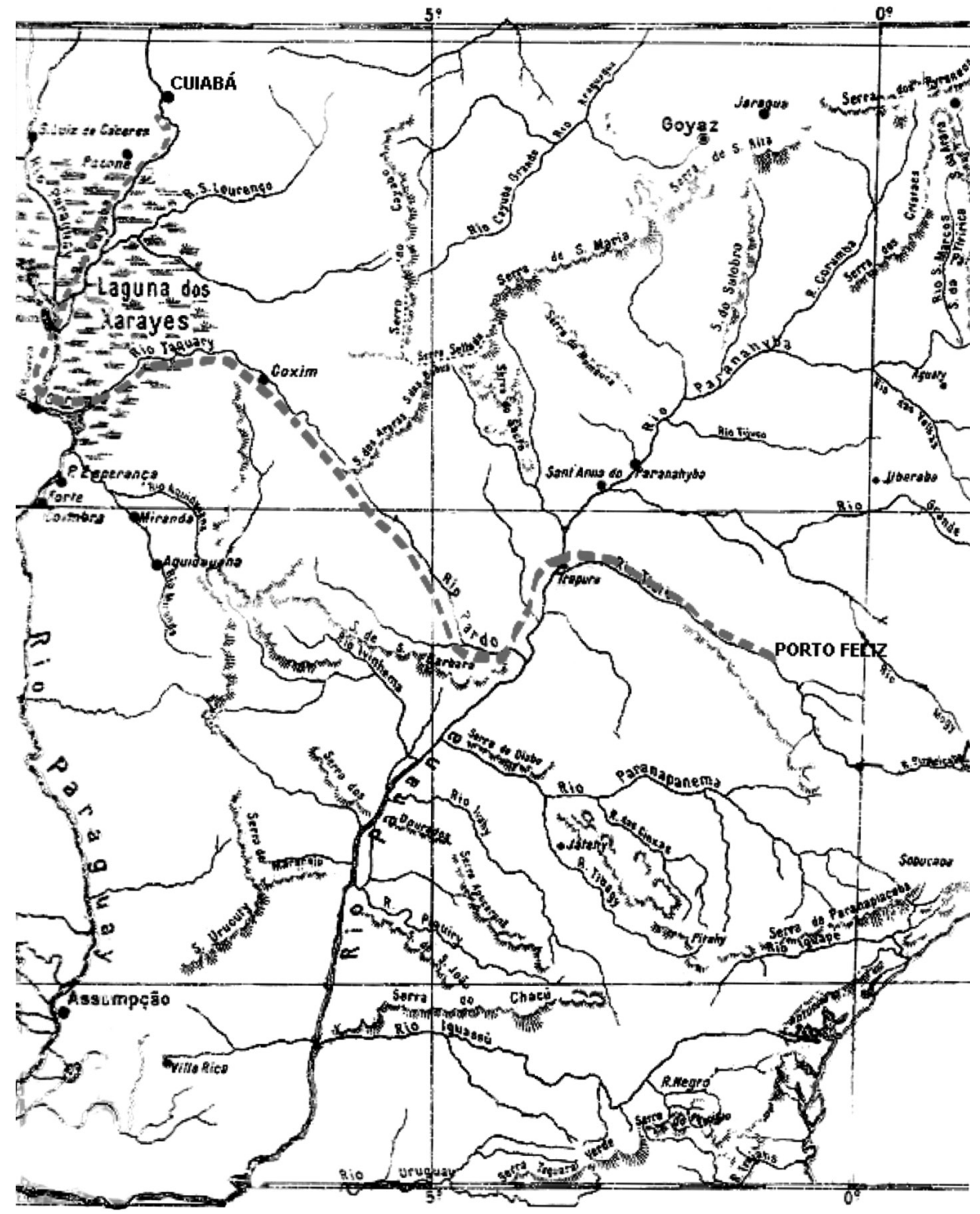

Fonte: ARRUDA, José Robson de. Atlas históricos (Recorte). 17ª. Ed. São Paulo: Ática,2008, p. 17. 
Dentre os varadouros, o mais curto era o que se apresentava entre o rio Pardo e o Coxim (formador, este, do Taquari), passando pelo ribeirão chamado Camapuã, que deu origem, na década de 1720, à fazenda de Camapuã na capitania de Mato Grosso. Segundo Amorim

A mesma época da fundação de Camapuã, os monçoeiros sentiam a necessidade de criar um arraial no pouso próximo à desembocadura do Coxim com o Taquari e que, nesse fator, esteja a gênese de um efêmero povoamento liderado por João de Araújo Cabral ${ }^{51}$.

Cabe acrescentar que o fluxo migratório proporcionado por essas rotas monçoeiras para a capitania de Mato Grosso permitiu o comércio de diferentes artigos na área mineradora e colocou esta em comunicação com as capitanias vizinhas de Goiás e Minas Gerais. Muitas dessas mercadorias eram, em alguns trechos internos, transportadas em vias terrestres, em carros de boi ${ }^{52}$. Como assinala Lenharo, foi só após a extinção das monções do norte ${ }^{53}$, em 1778, que "essas vias terrestres puderam se firmar no intercâmbio da capitania mato-grossense com o litoral brasileiro" 54 . Essas "estradas", abertas desde 1736-1737, ligavam a capitania de Mato Grosso à de Goiás e, daí, às de Minas Gerais, São Paulo e Rio de Janeiro. Elas contribuíram para a formação do mercado interno e para a utilização dos muares como meio essencial de transporte no sul de Mato Grosso.

\footnotetext{
${ }^{51}$ AMORIM, Marcos Lourenço de. O segundo eldorado brasileiro. navegação fluvial e sociedade no território do ouro: de Araritaguaba a Cuiabá (1719-1838). 2004. p. 173. Dissertação (Mestrado em História). Universidade Federal do Mato Grosso do Sul, Dourados, 2004.

${ }^{52} \mathrm{Na}$ década de 1750 , “as mercadorias que vinham do litoral brasileiro para a capitania mato-grossense eram transportadas em carretas puxadas por bois, conforme testemunhou o capitão-general Antônio Rolim de Moura em 1750". SILVA, Hermano Ribeiro. Garimpeiros de Mato Grosso: viagens ao sul do Estado e ao lendário rio das Garças. São Paulo: J. Faguntes, 1936. p. 84.

${ }^{53}$ A expressão "monções do norte" é tida, por muitos autores, como desconhecida, uma vez que se tem reconhecido apenas as monções cuiabanas; de acordo com GOES FILHO, Synésio Sampaio. Navegantes, bandeirantes, diplomatas. São Paulo: Martins Fontes, 1999. p.158, aquelas monções teriam durado menos que as cuiabanas, porém, declinando juntas no século XIX. Veja-se, ainda, DAVIDSON, M. David. How the Brazilian West was won: freelance and state on the Mato Grosso frontier, 1732-1756. In: Alden, Dauril (Ed.). Colonial roots of modern Brazil. Berkeley: University of California Press, 1973. p. 18 e SILVA, Jovam Vilela da. Mato Grosso - mistura de cores: política de povoamento e população na capitania de Mato Grosso - século XVIII. Cuiabá: Editora da Universidade Federal de Mato Grosso, 1995. p. 40.
}

${ }^{54}$ LENHARO, Alcir. Op. Cit., p. 20 e ss. 
Todavia, mesmo com a abertura dessas vias terrestres, ainda eram mais viável o transporte fluvial. Grande parte do lucro conseguido pelos monçoeiros durante suas jornadas nas Minas do Cuiabá era gasto na compra de alimentos para a "torna-viagem", isto é, para o retorno ao litoral. Esses alimentos eram produzidos com a agricultura temporária ou de subsistência, praticada, em parte, pelos próprios mineradores e pelos comerciantes locais. De acordo com Taunay, em seus Relatos $^{55}$, esses produtos tinham preços muito acima dos cobrados pelos monçoeiros em outros trechos de seus percursos. Isso propiciava a permanência de moedas na própria capitania, pois os alimentos consumidos em Mato Grosso eram pagos em ouro o que, por sua vez, gerava elevado custo de vida na capitania no final dos setecentos.

Porém, os monçoeiros não tinham muito a reclamar, pois já seus preços eram também bastante elevados. Argumentavam, em defesa dos valores cobrados que, além das já conhecidas razões como riscos, distâncias e custos, os fretes, taxas e impostos aduaneiros também provocavam o aumento nos preços dos seus produtos. É assim que, em 1745, um alqueire de sal embarrilado custava, na capitania do Rio de Janeiro, $3 \$ 500$ e, em Cuiabá, $30 \$ 440^{56}$. Grandes diferenças também se verificavam nas demais mercadorias consumidas na capitania de Mato Grosso, o que recompensava, em parte, toda a aventura de travessia pelo sertão adentro.

Além disso, tais preços diferenciados eram praticados mesmo no interior da capitania. A título de comparação, pode-se observar os casos da Vila Real do Senhor Bom Jesus de Cuiabá (sul) e da Vila Bela da Santíssima Trindade (oeste): O capitão-general Antônio Rolim de Moura Tavares, em 1755, chegou a denunciar essas diferenças intra-regionais às autoridades da Colônia, quando escreveu que:

Uma carga de três arrobas de sal vindas do Rio de Janeiro chegava a Vila Bela a um preço de dezessete oitavas; (sendo uma oitava equivalente a 3,6 gramas de ouro), em Cuiabá se pagava a metade pela mesma carga, enquanto nessa cidade por uma alavanca se pagava duas oitavas, em Vila Bela não saia por menos de cinco oitavas. Uma libra de pólvora custava meia oitava em Cuiabá

\footnotetext{
${ }^{55}$ TAUNAY, Afonso d'E. Relatos Monçoeiros. Belo Horizonte: Itatiaia, 1981. p. 32.

${ }^{56}$ CORREA FILHO, Virgílio. Op. cit., p. 276.
} 
e duas e meia a três oitavas em Cuiabá. Preço de uma libra de aço era de meia pataca de ouro em Cuiabá e chegava a doze em Vila Bela e um barril de açúcar valia nove oitavas em Cuiabá e vinte e quatro em Vila Bela ${ }^{57}$.

O comércio no interior da província cresceu nas últimas décadas dos setecentos, com a produção de alimentos como: carne, peixe, farinha de mandioca, arroz, feijão, milho, açúcar, aguardente e rapadura, produção esta realizada em sítios e fazendas da capitania de Mato Grosso. Foi a partir dessa época que muitos mineradores, devido ao decréscimo da produção aurífera, solicitaram sesmarias (correspondentes a três mil braças de terras) e transferiram seu capital, sua mão-de-obra escrava e bens materiais para a agropecuária. Na época, este deslocamento encontrou testemunhos como o que se segue:

Estão as minas cansadas; os seus jornais já não cobrem as despesas do ferro, aço, alimento e vestuário dos escravos, e por isso o mineiro já desesperado se passa a lavrador ou criador de gado, ou erige um engenho de aguardente e açucares, lamentava-se em 1802, o cuiabano João Manoel de Siqueira ${ }^{58}$.

Essa transferência de capital para atividade agrícola e a introdução de produtos regionais no mercado da capitania permitiram considerável queda nos preços dos alimentos consumidos neste período. Só para exemplificar, "em 1754 uma libra de carne estava a setenta réis, já para o ano de 1778, a mesma libra de carne custava trinta e cinco réis" $"$.

Diante disso, evidencia-se que o comércio monçoeiro inseriu a produção mineira da capitania mato-grossense no mercado interno luso-brasileiro e proporcionou a circulação de pessoas e mercadorias manufaturadas vindas do litoral para o interior da mesma, durante as últimas décadas do século XVIII.

Essa abordagem de questões econômicas advindas do ouro e do movimento monçoeiro, portanto, contesta a abordagem oficial do tema, a qual explica o atra-

\footnotetext{
${ }^{57}$ Idem, p. 325.

${ }^{58}$ ROSA, Carlos. O processo de independência em Mato Grosso e a hegemonia cuiabana. Cuiabá: SEDUC, 1976. p. 13-14.

${ }^{59}$ ARRUDA, Elmar Figueiredo de. Formação do mercado interno em Mato Grosso: século XVIII. 1987. Dissertação (Mestrado em História). Pontifícia Universidade Católica, São Paulo, 1987. p. 90.
} 
so da capitania com base na tese do "isolamento" econômico, do distanciamento de Mato Grosso em relação aos centros decisórios do país.

Procuramos demonstrar, neste texto que as idéias de isolamento, estagnação econômica e economia exclusivamente de subsistência em relação a Mato Grosso não tinham fundamentos. Acreditando que, apesar do forte impacto sofrido na economia com o declínio da mineração, Mato Grosso conseguiu reagir e levar adiante uma reorganização nas atividades econômicas que já vinham se desenvolvendo: a pecuária, a agricultura, as atividades mineradoras e o comércio intra-regional, inter-regional e internacional. 